\title{
TIME TO RAISE THE DEVIL
}

\section{A horrible facial cancer is decimating the Tasmanian devil population. But researchers in Australia think they have found a way to save the species. Carina Dennis reports.}

\begin{abstract}
C
hecking her research traps at dawn, Billie Lazenby was saddened to find a female Tasmanian devil with a face marred by cancerous lumps. She had contracted devil facial-tumour disease, a deadly transmissible cancer that is threatening the survival of this feisty marsupial.

When reviewing her records later that night, Lazenby, who is part of a scientific team monitoring the devils, was astonished to find that the animal, nicknamed Half pea, had been recorded nearly a year previously as having the disease. This made her one of the longest survivors the team had ever encountered. The fact that Half pea had resisted the tumour for at least twice as long as most other devils meant she might hold a clue for scientists trying to help the species. "Amid this heartbreaking background of losing so many devils,
\end{abstract} suddenly this animal pops up and it's like, 'wow, maybe there is hope," says Lazenby.

Since this discovery in June 2005, the team has found two other partly resistant females, and researchers now hope to identify the genetic and immunological factors that give
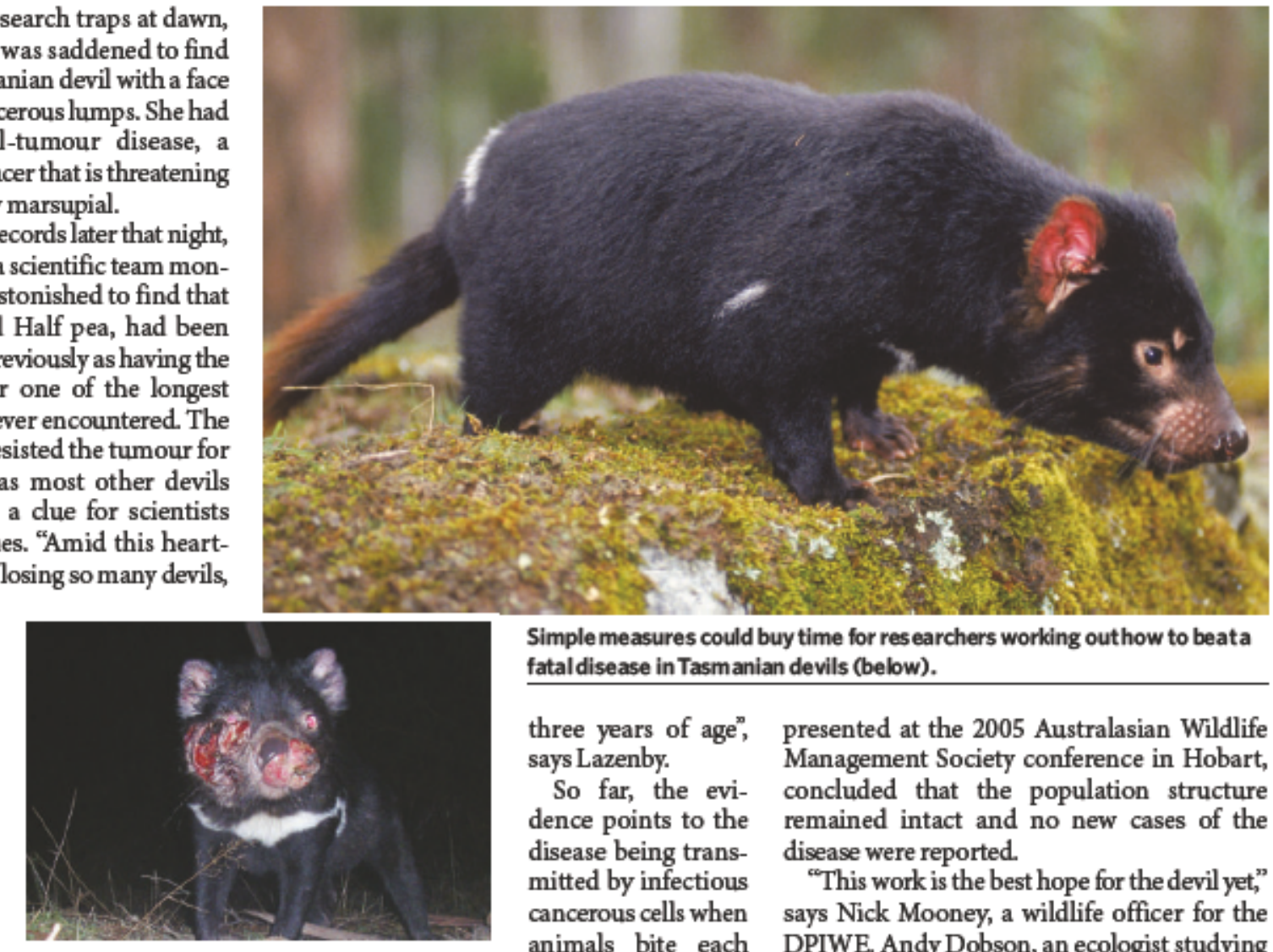
devils (Sarcophilus harrisii) a better chance of fighting the disease. It is a long-awaited piece of good news after a decade of helplessly watching the animals decline. Although longterm strategies for tackling the problem are some way off, other teams have discovered a way to limit the spread of the disease at least.

\section{Deadly love bites}

Lazenby, a scientific officer at the Tasmanian state government's Department of Primary Industries, Water and Environment (DPIWE), based in Hobart, is part of a team led by Clare Hawkins that traps and checks devils for signs of the cancer. A severely diseased devil is a grotesque sight: large tumours protrude from the face and neck, sometimes pushing out teeth and invading eye sockets. As the tumours interfere with feeding, the animals become emaciated and usually die within six months of showing lesions.

First documented by a wildlife photographer in 1996, the cancer has contributed to the deaths of up to $80 \%$ of infected devil populations in Tasmania ${ }^{1}$, the only place in the world where the animal is found. Devils normally have a life expectancy of about five years but " now it's rare to see an animal older than others' faces in fights or during their tempestuous courtship ${ }^{2}$. In the long-term, a vaccine or therapy will be needed and this is where animals showing some resistance to the tumours may be invaluable.

What's more, devils living in western Tasmania, which seem to be genetically distinct from their eastern cousins ${ }^{3}$, have so far remained free of the disease. Stephen Pyecroft, a veterinary pathologist at the DPIWE's animal-health laboratories in Mount Pleasant, is now scrutinizing the genes of devils from different regions to look for any natural genetic variation that may confer resistance.

But in the short term, the devils' best chance lies with the work of Menna Jones, a biologist at the DPIWE and the University of Tasmania in Hobart, who is investigating whether removing sick animals from wild populations suppresses the disease.

Jones has just completed a pilot study on two connected peninsulas on Tasmania's southeastern coast. These are ideal for restricting the movement of devils because they are separated from the mainland by a single bridge. She removed all infected animals from a 120-square-kilometre region in the peninsulas, and her unpublished results, presented at the 2005 Australasian Wildlife Management Society conference in Hobart, concluded that the population structure remained intact and no new cases of the disease were reported.

"This work is the best hope for the devil yet," says Nick Mooney, a wildlife officer for the DPIWE. Andy Dobson, an ecologist studying infectious diseases at Princeton University, New Jersey, agrees: "The initial results are giving us grounds for optimism.

\section{Total wipe-out}

Jones is now conducting a larger two-year study to completely eradicate the disease from the peninsulas. "If successful, this will be the only disease-free reserve of Tasmanian devils," says Jones. They will safeguard the bridge against roaming devils and set up remote cameras across the region to detect any diseased animals that manage to avoid trapping.

However, it's not clear that this approach will work for all areas. ${ }^{\text {In }}$ a larger open system, where animals can come and go, you may be pissing against the wind," says Mooney.

Others are optimistic that tackling the problem from a multitude of angles will ultimately save the devil. "You can be a pragmatic scientist about it," says Pyecroft, "but you also have to have a bit of faith.

Carina Dennis is Nature's Australasian correspondent.

1 Hawkins, C. E etal. Biol. Conserx (in press)

2. Pearse, A-M. \& Swift, K.Nature 439,549 (2006)

3 Jones, M. E, Paetkau D, Geffen, E \& Moritz, C.Mol. Ecal. B, 2197-2209 (2004) 